\title{
Generalized Mediterranean Annual Water Yield Model: Grunsky's Equation and Long-Term Average Temperature
}

\author{
Francisco L. Santos ${ }^{1}$ and Richard H. Hawkins ${ }^{2}$
}

\begin{abstract}
To estimate mean annual water yield on ungauged watersheds, regional regression equations have been developed that are a function of upstream area, precipitation, and temperature, and are commonly used. In this study, the 100-year old Grunsky equation is used as the foundation for a fully implemented generalized Mediterranean water yield model that is based on long-term annual precipitation and temperature. The work here (1) extends and generalizes Grunsky's equation beyond its original conditions, (2) establishes an underlying hydro-climate generalized model for average annual Mediterranean watershed water yield and loss calculation, and (3) applies the validated model to estimate watershed water yield and predict potential water yield response to watershed temperature and precipitation. The water yield model was applied to watersheds in coastal California, southern France, and Portugal, but might be applied to other Mediterranean sites for which precipitation and temperature data are available. It also can be used to examine the spatial and temporal variability for water yield and predict the effects of long-term climate changes at the regional scale. DOI: 10.1061/(ASCE)HE.1943-5584.0000402. ( 2011 American Society of Civil Engineers.
\end{abstract}

CE Database subject headings: Hydrologic models; Portugal; Mediterranean Sea; California; Water resources; Rainfall; Runoff; History.

Author keywords: Hydrological models; Portugal; Water resources; Rainfall; Runoff; Grunsky; History of hydrology.

\section{Introduction}

\section{Grunsky's Equations}

A recurring and almost classic task in surface water hydrology is the estimation of long-term annual yield (or flow) from ungauged watersheds. The unfortunate fact is that there is no single good, easy, confident method to do it, and most watersheds are ungauged. The gauged stream is a rare exception. However, total surface water yield is a frequently sought basic measure of the available water resource, and serves as a point of departure for more detailed water budgeting, including ground water studies. For example, in reservoir planning, no matter how clever the operation is, or how large the storage is, no more can be withdrawn over the long run than what flows in (i.e., the average annual flow). Thus, a basin's water yield is the upper limit of possible water resource development. It is also necessary for describing river flows of shorter durations or distributions, as well as for water quality or sediment studies. It is an essential component of a basin's hydrologic budget.

The basic considerations are precipitation into the watershed, and water losses via evaporation and vegetative water use. The residual that escapes the losses is water yield, seen as stream flow, or

\footnotetext{
${ }^{1}$ Associate Professor, Instituto de Ciências Agrárias e Ambientais Mediterrânicas (ICAAM), University of Évora, Apartado 94, 7002-554, Évora, Portugal (corresponding author). E-mail: fls@uevora.pt

${ }^{2}$ Professor, Hydrology and Water Resources, School of Renewal Natural Resources, 325 Bio Sciences East, The University of Arizona, Tucson, AZ 85721. E-mail: rhawkins@ag.arizona.edu

Note. This manuscript was submitted on August 12, 2010; approved on March 29, 2011; published online on March 31, 2011. Discussion period open until April 1, 2012; separate discussions must be submitted for individual papers. This paper is part of the Journal of Hydrologic Engineering, Vol. 16, No. 11, November 1, 2011. CASCE, ISSN 1084-0699/2011/ $11-874-879 / \$ 25.00$.
}

$$
Q=P-L
$$

where $P=$ average annual precipitation; $Q=$ average annual runoff; and $L=$ watershed losses via evapotranspiration. In general, the units are in $L / T$; historic work was in in./year.

\section{Grunsky's Assertions}

As a part of the emerging science of hydrology and the development of the nation's water resources, there was a blossoming of interest in the topic in the early 1900s. The problem was faced by planners looking to enhance local water supply in the San Francisco peninsula, and Grunsky (1908) made the following paraphrased observation from his experiences and the limited information at his disposal: "The percent of annual rain that becomes runoff is equal to the inches of rainfall, up to 50 inches of rain," and "above 50 inches, the runoff is the rain less 25 inches." The first of these assertions becomes $Q / P=P / 100$, leading easily to

$$
Q=P^{2} / 100, \quad P \leq 50
$$

where $Q=$ average annual runoff (in./year), $P=$ average annual rainfall (in./year). The "above 50 inches" portion becomes

$$
Q=P-25, \quad P \geq 50
$$

This proviso avoided unnatural or outrageous results that Grunsky surely foresaw beyond that point. First, if $P>50$ in Eq. (2a), then an increment of additional rain calculates more than that increment of additional runoff, an intuitively unreasonable nuance. In the extreme of $P=100$, then $Q=100$, suggesting no losses, or that all rain becomes runoff.

Gunsky's equations are Eqs. (2a) and (2b), a two-part relationship, originally found for the conditions of central coastal California near San Francisco and marked by a distinct seasonal (or Mediterranean) climate. Given the humble informal origins 
and its approximate nature, it might also be called "Grunsky's rule-of-thumb." It was not stated as formally as given here, and there was little supporting data offered.

Note that these original statements were in U.S. conventional units (inches), which prevailed at the time, and which enhanced the simple charm via the mnemonically pleasing "percent runoff equals inches." As will be seen, it nevertheless described a natural process, which should hold equally well regardless of the units system. In keeping with current convention, metric units will be used jointly in the following.

\section{Generalization}

Insofar as the above was observed for Mediterranean conditions, a generalized hypothesis of Grunsky's assertion should give insights to annual yields and their applications for Mediterranean settings elsewhere. Here, the locations examined are in California, Southern France, and Portugal.

Eq. (2a) and (2b) can be restated generally as

$$
\begin{gathered}
Q=\alpha P^{2}, \quad P<P^{*} \\
Q=P-L^{*}, \quad P>P^{*}
\end{gathered}
$$

where $P^{*}$ and $L^{*}$ play the role of the $50 \mathrm{in}$./year $(1,270 \mathrm{~mm} /$ year $)$ threshold rainfall and $25 \mathrm{in}$./year $(635 \mathrm{~mm} /$ year $)$ constant loss held in the original assertion, with the coefficient $\alpha$ fulfilling the role of $1 / 100$ in the algebraic $100 Q / P=P$ original Grunsky's statement, now with the dimensions of $\mathrm{mm}^{-1}$. Conversion between the two systems is simply $\alpha\left(\mathrm{mm}^{-1}\right)=\alpha\left(\right.$ in. $\left.^{-1}\right) / 25.4$. Thus, in metric units (millimeters) with $P$ in millimeters, Grunsky's local case becomes $100 Q / P=P / 25.4$.

The constant loss $L^{*}$ above the critical precipitation $P^{*}$ begins where the slope of the $P: Q$ in Eq. ( $3 a$ ) becomes unity. Thus, differentiating and setting equal to 1 , and solving for $P$ gives

$$
P^{*}=1 /(2 \alpha)
$$

From this

$$
Q^{*}=\alpha\left(P^{* 2}\right)=1 / 4 \alpha
$$

and

$$
L^{*}=P^{*}-Q^{*}=1 /(4 \alpha)
$$

Thus, for the general case of Grunsky's equation

$$
\begin{gathered}
Q=\alpha P^{2} \quad P<1 /(2 \alpha) \\
Q=P-1 /(4 \alpha) \quad P>1 /(2 \alpha)
\end{gathered}
$$

A plot of the general function for various values of $\alpha$ is shown in Fig. 1. The quadratic part $Q=\alpha P^{2}$ pertains for $Q<P / 2$, and the linear part $Q=P-L^{*}$ applies for $Q>P / 2$, as a result of $Q^{*} / P^{*}=1 / 2$.

Knowledge of local data and hydrologic behavior is the hydrologist's stock-in-trade. Thus, insights to reasonable and unreasonable estimates of annual yields can be obtained from specific $P: Q$ data. The process is simple: with known $P$ and $Q$ values, presumed to be valid and representative, Eq. (7) and Eq. (8) can be solved for $\alpha$, and from that, $L$ can be solved. However, the two equations represent one continuous relationship, so if fitting with multiple data points exists on both sides of $P^{*}$, then both of the equations can be applied, hopefully with the same value of $\alpha$ prevailing above and below $P^{*}$. It is intended for use with locally based values of $\alpha$, and at the planning level.

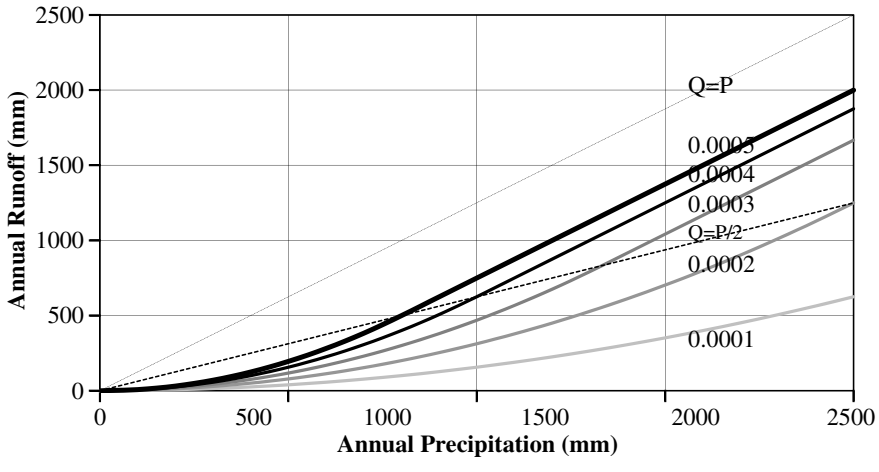

Fig. 1. Grunsky's equation plot for various values of the coefficient $\alpha\left(\mathrm{mm}^{-1}\right)$; also represented are the $Q=P$ and $Q=P / 2$ lines

From the above, the coefficient $\alpha$ is a characterizing measure of the watershed's annual water yield response to annual precipitation, with the dimensions of $L^{-1}$. That is, it is a runoff response parameter characterizing the watershed and its climate. For Grunsky in the San Francisco area, its value was $1 / 100$ in. $^{-1}\left(0.000394 \mathrm{~mm}^{-1}\right)$. There is also a general ecology interpretation to $L$ and $L^{*}$. To some interests, the component of concern may be the losses, or $L=P-Q$. This is the water that does not become runoff, but stays on the watershed, and is used via photosynthesis in trees, grass, and crops growth. This process also stores a small part of the incoming solar energy in the chemical bonds of the plants. Some part also goes to evaporation and in some cases to ground water recharge. These are

$$
\begin{array}{cc}
L=P(1-\alpha P) & P<1 /(2 \alpha) \\
L=1 /(4 \alpha)=L^{*} & P>1 /(2 \alpha)
\end{array}
$$

As modeled in the equations, an important feature of this is that the losses seem to approach a constant with increasing precipitation, here represented by $L^{*}$. A plot of the general function for various values of $\alpha$ is shown in Fig. 2 .

This general theme was recognized by Langbein (1949) in the following: "The numerical difference between precipitation and runoff for a given temperature increases with precipitation, ultimately reaching a constant that represents the limiting or optimum evapotranspiration, which is here considered as governed primarily by the temperature but may be more generally related to such factors as insolation, wind movement, relative humidity, and other

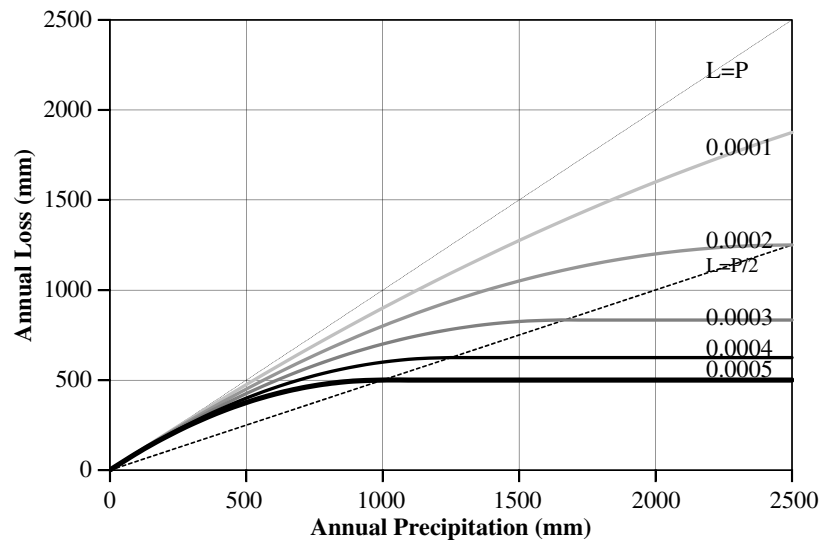

Fig. 2. Grunsky's loss equation plot for various values of the coefficient $\alpha\left(\mathrm{mm}^{-1}\right)$; also represented are the $L=P$ and $L=P / 2$ lines 
climatic elements." Thus $L^{*}$ is a joint/related (to $\alpha$ ) characterizing descriptor of the watershed and climate.

Grunsky's original application was straightforward and local, and gave no values for $\alpha$ beyond the implied value of $0.01 \mathrm{in}^{-1}$. Indeed, he did not generalize or formalize, and in 1915 he published in the ASCE Transactions (Grunsky 1915) a second/revised approximation of a wider California " $\alpha$ " (he did not call it that) of about 0.0089 in. $^{-1}\left(0.0003504 \mathrm{~mm}^{-1}\right)$. This was given as a graph with no data points shown. Grunsky's equation is a simple form of a geographic-regression-regional equation for annual runoff based on annual precipitation.

\section{Grunsky's Equation and Other Regional Water Yield Models}

\section{Justin}

Many others such models have been crafted since Grunsky's time. Justin (1914) was a contemporary of Grunsky, and was concerned with similar matters. Studying streams in the northeastern United States and starting with $C=k R^{2}$, Justin (1914) came to

$$
C=0.934 S^{0.155} R^{2} / T
$$

in which $C=$ annual runoff, in inches, on the watershed ( $Q$ here); $R=$ annual rainfall, in inches on the watershed ( $P$ here); $S=$ slope of the watershed; and $T=$ mean annual temperature. Inasmuch as slope determines topography, and topography largely determines the character of the vegetal covering, this formula takes into account all the important factors which the writer found to cause variation in transpiration and ground-surface evaporation. This formula has the additional advantage of being based solely on observed data, and is therefore believed by the writer to apply safely throughout the territory for which it was derived. This can be rephrased in terms used here as

$$
Q=\left(0.934 S^{0.154} / T\right) P^{2}
$$

With the $P^{2}$ term, Eq. (11) is directly comparable to Grunsky's equation with $\alpha=0.934 S^{0.154} / T$. No dimensions are given in the previous direct quote, but later discussion by Horton (1914) shows the area is in $\mathrm{mi}^{2}$, the elevations in feet, and temperature in ${ }^{\circ} \mathrm{F}$. $P$ and $Q$ are stated to be in in./year. With no upper limits given on $P$, the Justin paper gives values of $k$ ( $\alpha$ here) for watersheds in New York, New Jersey, West Virginia, Connecticut, and southern Canada.

\section{Vogel et al.}

Perhaps the most comprehensive effort has been the recent nationwide work of Vogel et al. (1999), with long-term data from 18 regions in the United States, which used not only $P$, but temperature $\left({ }^{\circ} \mathrm{F}\right)$ and drainage area $(A)$ for inputs as well in multiple regressions in logarithmic form. For the conterminous U.S., the regression equations for estimation of the mean annual stream flow are of the form

$$
Q_{m}=e^{a} A^{b} P^{c} T^{d}
$$

where $Q_{m}=$ estimated mean annual flow $\left(\mathrm{m}^{3} \mathrm{~s}^{-1}\right) ; e=$ base of natural logarithms; $A=$ drainage area above a point $\left(\mathrm{km}^{2}\right) ; P=$ mean annual precipitation for the drainage area (mm/year); $T=$ mean annual temperature for the drainage area (tenths of ${ }^{\circ} \mathrm{F}$ ); and $a$, $b, c$, and $d=$ region-specific coefficients. The 18 regions used in developing regression equations for the conterminous United States correspond to the hydrologic regions, as defined by the
USGS and reported in Seaber et al. (1987). For California, the exponents for the regional annual mean flow rate regression equation are 8.4380, 0.97398, 1.99863, and 1.5319, respectively.

The Vogel et al. (1999) regression results could be simplified and expressed in consistent hydrologic budget terms, making them comparable to Grunsky's equation form. When their exponential formulations for $Q$ are set equal to $\alpha P^{2}$, an implied $\alpha$ may be obtained by back-calculating. However, this was not done here because of the additional variables Vogel et al. used, and because their fittings were done with logarithmic values. The two methods are not directly comparable.

\section{Others}

Sellers (1969) gave regional values under a different nomenclature and are shown in Table 1. This table is almost the sole available reference listing of $\alpha$ in textbook form. "Central Coastal California" from Grunsky's founding works, with $\alpha=0.000394 \mathrm{~mm}^{-1}$ $\left(0.01\right.$ in. $\left.^{-1}\right)$ must be added to this. While these are in general alignment with data-derived values, Sellers does not give sources for the above. Another attempt at table values based on the evaluation of results is given by Gifford et al. (1976).

An analysis of annual runoff from watersheds in the western United States by Hawley and McCuen (1982) led to a series of exponential equations similar to those later developed by Vogel et al. (1999). Hawkins (1991) showed that annual runoff from 11 river basins in central Arizona could be well represented by $Q=0.004 P^{2}$ (using U.S. conventional units). This is clearly in line with Grunsky's precedents, though not a classical Mediterranean climate.

Not surprisingly, temperature seems to be quite important in establishing $\alpha$. Both Justin's (1914) and Vogel et al.'s (1999) expressions relate runoff and mean annual flow to temperature, consistently reinforcing the general role of temperature as inverse to runoff. The Hawley-McCuen equations (1982) do not contain temperature itself, but do include basin elevation as a positive item in several expressions, reflecting the negative relationship generally found between elevation and temperature.

\section{California $\alpha$ Values Extended}

In a study of geologic sedimentation and fault movement in California, Kolterman and Gorelick (1992) summarized the longterm runoff and climate of coastal streams from the Smith River in the north to the San Luis Rey River in the south. The digital data were not included in their journal paper, but was scaled from plots provided, and is shown in Table 2. From these representative California $P$ and $Q$ values, Eq. (7) and Eq. (8) were solved for $\alpha$ value for each of the basins, and from that, $L$ values where obtained. While this gave a wide scatter of $\alpha$, it was found to be very closely associated with the average annual temperatures $T\left({ }^{\circ} \mathrm{C}\right)$ via the equation

$$
\alpha(T)=0.00075-0.000036 T
$$

Table 1. Estimated Regional Values of the Coefficient $\alpha$

\begin{tabular}{lcc}
\hline Region & $\alpha\left(\mathrm{mm}^{-1}\right)$ & $\alpha\left(\right.$ in. $\left.^{-1}\right)$ \\
\hline $\begin{array}{l}\text { Great Plains, Texas, Florida, } \\
\text { Southwest Desert }\end{array}$ & $<0.000197$ & $<0.005$ \\
East Central states and & $0.000197-0.000394$ & $0.005-0.010$ \\
West Coast & $0.000394-0.000787$ & $0.010-0.020$ \\
Great Lakes, New England, & & \\
Northern Appalachians & $>0.000787$ & $>0.020$ \\
Rocky and Sierra Nevada Mountains &
\end{tabular}


Table 2. Average Annual Precipitation $(P)$, Runoff $(Q)$, Area, Temperature $(T)$, and $\alpha$ for California Coastal Watersheds from Kolterman and Gorelick (1992) Scaled Data

\begin{tabular}{|c|c|c|c|c|c|c|}
\hline River & $P(\mathrm{~mm})$ & $Q(\mathrm{~mm})$ & $\operatorname{Area}^{\mathrm{a}}\left(\mathrm{km}^{2}\right)$ & $T\left({ }^{\circ} \mathrm{C}\right)$ & $\alpha\left(\mathrm{mm}^{-1}\right)$ & $\alpha$ (in. $\left.^{-1}\right)$ \\
\hline Smith & $2,770.1$ & $2,140.0$ & 1,590 & 8.51 & 0.00040 & 0.0101 \\
\hline Klamath & $2,150.1$ & $1,549.9$ & 31,344 & 8.69 & 0.00042 & 0.0106 \\
\hline Redwood Cr & $2,009.9$ & $1,389.9$ & 717 & 9.01 & 0.00040 & 0.0102 \\
\hline Mad & $1,640.0$ & $1,059.9$ & 1,256 & 9.5 & 0.00043 & 0.0109 \\
\hline Eel & $1,500.1$ & 871.0 & 8,116 & 10 & 0.00040 & 0.0101 \\
\hline Navarro & 1,329.9 & 676.9 & 759 & 10.6 & 0.00038 & 0.0097 \\
\hline Russian & $1,150.1$ & 531.1 & 3,505 & 11.0 & 0.00040 & 0.0102 \\
\hline Cache $\mathrm{Cr}$ & 785.1 & 164.1 & 2,950 & 12.6 & 0.00027 & 0.0068 \\
\hline Napa & $1,039.9$ & 398.0 & 565 & 11.6 & 0.0003 & 0.0093 \\
\hline Alameda $\mathrm{Cr}$ & 570.0 & 89.9 & 1,640 & 12.6 & 0.00028 & 0.0070 \\
\hline Pajaro & 462.0 & 46.7 & 3,072 & 14.2 & 0.00022 & 0.0056 \\
\hline Salinas & 661.9 & 81.8 & 10,766 & 13.6 & 0.00019 & 0.0047 \\
\hline San Antonio & 645.9 & 170.9 & 562 & 11.6 & 0.00041 & 0.0104 \\
\hline Santa Clara & 462.0 & 39.1 & 2,997 & 15.3 & 0.00019 & 0.0047 \\
\hline Santa Margarita & 385.1 & 19.1 & 1,441 & 17.9 & 0.00013 & 0.0033 \\
\hline San Luis Rey & 437.9 & 18.0 & 1,443 & 17.9 & 0.00009 & 0.0024 \\
\hline
\end{tabular}

${ }^{\mathrm{a}}$ USGS California Hydrologic Data Report, 1996 (http://ca.water.usgs.gov/archive/waterdata/96/11042000.html).

This is presented in Fig. 3, with $r^{2}=0.894$ and $S E=$ $0.000039 \mathrm{~mm}^{-1}$. A strong fit from such a wide range of sites suggests an underlying hydro-climatic relation that might be extended to broader application. However, insofar as these were all for a distinctly seasonal climate, caution would restrict its application only to other sites of such characteristics.

Thus, the hypothesis here is Grunsky's general model [i.e., Eqs. (7) and (8)] and the $\alpha(T)$ equation [Eq. (14)] found for California coastal watersheds.

\section{Tests of the Generalized Mediterranean Water Yield Model}

Mediterranean-type climates are found in the territories fringing the Mediterranean Sea, in California, Central Chile, and the southernmost strips of South Africa (Cape Province) and Australia. According to Nahal (1981), it is a climate where "rainfall is concentrated in the cold or relatively cold seasons of the year, summer, the hottest season, being dry." Similarities are not restricted to climate trends, but also reflected in the physiognomy of the vegetation, in land use patterns, and frequently in the general appearance of the landscape (Di Castri 1981).

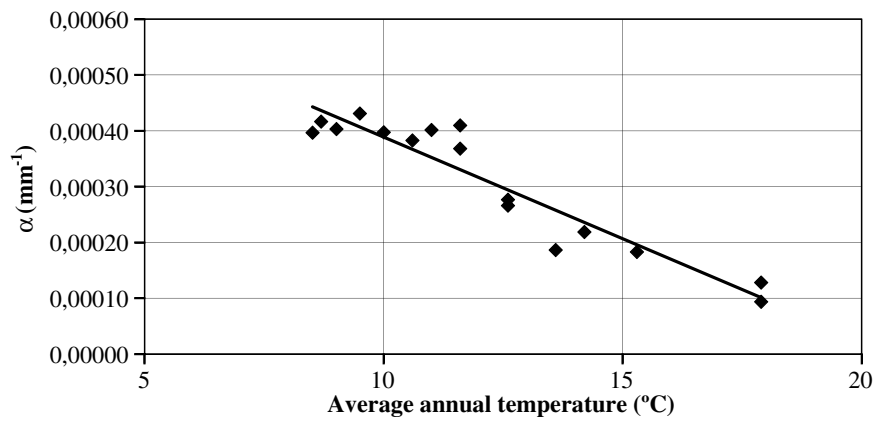

Fig. 3. Scatter plot for calculated coefficient $\alpha$ from coastal California and the corresponding average annual temperatures; solid line is a linear fit; $\alpha(T)=0.00075-0.000036 T ; r^{2}=0.894 ;$ and $S E=$ $0.000039 \mathrm{~mm}^{-1}$

\section{Southern France}

A limited test of the Mediterranean generality hypothesis model established with Eq. (14) was enabled with composited data from 4 small watersheds at the Collobrier site in southern France, described in Andréassian (1992). The Réal Collobrier research watersheds are located in the Maures mountains, approximately $6^{\circ} 20^{\prime} \mathrm{E}$ and $43^{\circ} 15^{\prime} \mathrm{N}, 20 \mathrm{~km}$ from the harbor of Toulon on the Mediterranean Sea. The subwatersheds are the drainage basins \#5 (Valescure), \#6 (Mauarets), \#7 (Vaubarnier), and \#8 (Rimbaud). Data were dailyrunoff time series and temperature from the weather station of Collobrières (Table 3). Computations were made using the water between 1969 and 1988 for the precipitation-runoff, and 1970 to 1983 for the temperatures. Using the Collobrier $P$ and $Q, \alpha$ is found to be $0.0003533 \mathrm{~mm}^{-1}\left(0.008974 \mathrm{in}^{-1}\right)$. Using Eq. (14), based on temperature alone, $\alpha$ value also calculates to $0.00036000 \mathrm{~mm}^{-1}$ $\left(0.0091440 \mathrm{in}^{-1}\right)$, falling very close to the California trend line (Fig. 3).

\section{Portugal}

More tests were done on data from 12 watersheds (Table 4) located from the north to the south of Portugal (Instituto da Água, I.P. 2009). Computations were made using the water years 1940/ 1941 to $1997 / 1998$ for the precipitation-runoff, and time series of more than 30 years for temperature (http://snirh.pt, option Dados Sintetizados $>$ Recursos Hídricos $>$ Climatologia $>$ Boletim de

Table 3. Average Watershed Area, Annual Precipitation $(P)$, Runoff $(Q)$, and Temperature $(T)$ for Réal Collobrier in Southern France (Andréassian 1992); the Composited Data from the Four Small Watersheds at the Collibrier Site Is Presented Subsequently

\begin{tabular}{lllc}
\hline Area $\left(\mathrm{km}^{2}\right)$ & $P(\mathrm{~mm})$ & $Q(\mathrm{~mm})$ & $T\left({ }^{\circ} \mathrm{C}\right)$ \\
\hline 9.25 & 1,233 & 498 & 11 \\
8.41 & 1,118 & 432 & 11 \\
1.52 & 1,088 & 498 & 11 \\
1.47 & 1,230 & 715 & 11 \\
\hline \multicolumn{3}{c}{ Composite } \\
\hline 20.65 & $1,175.30$ & 486.57 & 11 \\
\hline
\end{tabular}


Table 4. Average Watershed Characteristics (Length and Area), Annual Precipitation $(P)$, Runoff $(Q)$, Temperature $(T)$, and Grunsky $\alpha$ 's for Portuguese Watersheds (INAG, I.P. 2009)

\begin{tabular}{|c|c|c|c|c|c|c|}
\hline Watershed (river) & Length $(\mathrm{km})$ & Area $\left(\mathrm{km}^{2}\right)$ & $P(\mathrm{~mm})$ & $Q(\mathrm{~mm})$ & $T\left({ }^{\circ} \mathrm{C}\right)$ & $\alpha\left(\mathrm{mm}^{-1}\right)$ \\
\hline Ave & 91 & 1,388 & 1,522 & 695.2 & 13.9 & 0.00030 \\
\hline Douro & 927 & 97,667 & 908 & 291.6 & 13.5 & 0.00035 \\
\hline Guadiana & 720 & 67,254 & 597 & 42.6 & 16.4 & 0.00012 \\
\hline Lima & 135 & 2,518 & 1,780 & 795.9 & 13.6 & 0.00025 \\
\hline Lis & 40 & 850 & 855 & 99.8 & 14.8 & 0.00014 \\
\hline Mira & 124 & $1,575.3$ & 668 & 58.9 & 16.6 & 0.000132 \\
\hline Mondego & 229 & 6,653 & 1,132 & 380.6 & 14.5 & 0.00030 \\
\hline Nabão & 62 & 1,053 & 967 & 346.2 & 14.5 & 0.00037 \\
\hline Sado & 176 & 7,734 & 669 & 35.5 & 16.1 & 0.00008 \\
\hline Tejo & 891 & 80,906 & 799 & 122.9 & 15.6 & 0.00019 \\
\hline Tâmega & 184 & 3,310 & 1,336 & 669.9 & 13.2 & 0.00038 \\
\hline Zêzere & 248 & 5,062 & 1,089 & 261.7 & 14.8 & 0.00022 \\
\hline
\end{tabular}

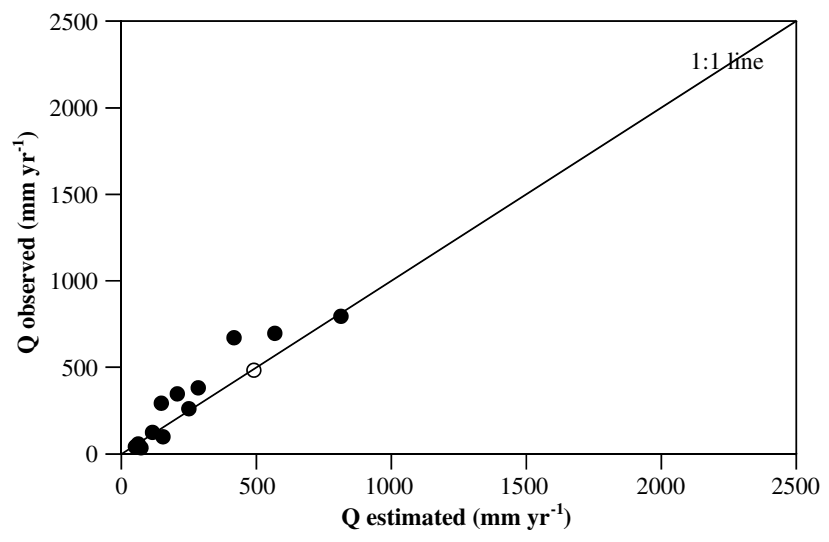

Fig. 4. Observed and derived annual water yield obtained with the Mediterranean generalized hypothesis model based on precipitation and temperature: Southern France (open circle); Portugal (solid circle); and solid line is the $1: 1$ line

Precipitação). Table 4 includes the calculated $\alpha$ values using the $P: Q$ parameters and the generalized Grunsky's equations.

Test of the Mediterranean generality hypothesis model with the Portugal watersheds data provided for $\alpha$ values, based solely on the analytical Eq. (14) for temperature. The predictive power of the model is shown in Fig. 4, where the observed $Q$ values from France and Portugal watersheds are regressed against $Q$ values calculated from the proposed Grunsky's generalized Mediterranean water yield model. With a $r^{2}=0.89$ for the Portugal watersheds, and the France watershed value falling very close to the $1: 1$ line, the good fit from such a wide range of sites allows for extending the model to Mediterranean basin encompassing the range of temperature and precipitation of the studied sites.

\section{Application}

With one distinct group of watersheds for the calibration of the Mediterranean model and another for validation, the generalization of results from our experimental watersheds to other areas, or to other ungauged catchments in the same regions, looks possible. From the generalized Mediterranean water yield model to a hypothetical ungauged Mediterranean watershed with long-term average temperature of $12.6^{\circ} \mathrm{C}$ and $570 \mathrm{~mm}$, annual rainfall will correspond to a $\alpha$ value of $0.0003 \mathrm{~mm}^{-1}$ from Fig. 3. From Fig. 1, the watershed is expected to yield $90 \mathrm{~mm} /$ year in runoff and, from Fig. 2, $473 \mathrm{~mm} /$ year that stay on the watershed, and is used via photosynthesis for vegetative growth of trees, grass, and crops. This process, as stated, also stores a small part of the incoming solar energy in the chemical bonds of the plants. Some part also goes to evaporation and, in some cases, to ground water recharge. Thus the losses, represented here by $L^{*}$, are a joint/related (to $\alpha$ ) characterizing descriptor of the watershed and climate. It may be used to evaluate the impacts of climate change on water yield. Additional watershed data from other Mediterranean regions is needed to fully validate the parameter's explanatory equations.

The proposed model gives insight about watershed rainfallrunoff relations driven by long-term annual mean temperature and does not thoroughly include in its development the potential effects of other watershed characteristics, such as land cover, or other meteorological factors, such as solar radiation. It is well known that watershed hydrologic responses are best described by climate (precipitation and evapotranspiration) and topographic features (Sun et al. 2001), with the redistribution of energy across latitude and elevation gradients resulting in distinct land cover communities also affecting the hydrologic processes and responses (Calvo-Alvarado and Gregory 1997; Lu et al. 2003; Sun et al. 2005). As in the study, watershed actual losses $(L)$ via evapotranspiration (ET) are controlled by precipitation and temperature, but also by potential evapotranspiration and vegetation ET characteristics (e.g., leaf area, transpiration rate per leaf area, species composition, tree age, and canopy interception capacity) (Sun et al. 2008). However, the parsimonious approach here relies on its transparency and simplicity to present valuable opportunities for the comparative study of other Mediterranean basins, and the regionalization of hydrological model parameters for comprehensive watershed planning procedures.

It should be noted that the model applies to long-term averages, not individual years, though some similar trends can be found. In addition, only watersheds (21 to $81,000 \mathrm{~km}^{2}$ ) encompassing the range of temperature $\left(9\right.$ to $18^{\circ} \mathrm{C}$ ) and precipitation (385 to $2,770 \mathrm{~mm}$ ) of the basins analyzed in the study have been used. Smaller watersheds may have local idiosyncrasies related to geologic or geographic or boundary happenstance (e.g., faults, springs, lakes, and swamps) that create nonrepresentative water budgets. Large watersheds are a collection of smaller watersheds, and the quirky variety of behaviors of small watersheds is averaged out. This smoothing is the rationale for compositing the four Collobrier watersheds in the above discussion. 


\section{Conclusions}

The problem of water yield from ungauged watersheds that faced planners looking to enhance local water supply on the San Francisco peninsula in the early 1900s was equated by Grunsky in his complete two-part relationship, which we call here Grunsky's equations. Grunsky's original application was straightforward and local, and gave no values for $\alpha$ beyond the implied value of 0.01 in. $^{-1}$. Given that the above was established for a specific set of conditions (i.e., the lands and climate found locally in the San Francisco area), an extended statement of Grunsky's equations was formulated and applied to California coastal streams. Plots of the general functions for various values of $\alpha$, the coefficient characterizing the watershed's annual water yield response to annual precipitation, are presented here. Found to be very closely associated with the corresponding watershed average long-term annual temperature, a Mediterranean model for $\alpha$ is also proposed. A link was established between the Mediterranean $\alpha$ model and the generalized Grunsky's equations, leading to development of a generalized water yield model for Mediterranean watersheds. Its main advantage, similar to Grunsky's approach, relies on its transparency and simplicity, enabling extending and transferring hydrological predictions from one Mediterranean area to another. By virtue of simple rainfallrunoff relationships, Mediterranean watershed water yields can be assessed, with the loss portion conveniently fitting meaningfully into concepts of general ecology, such as water use by resident vegetation. The predictive power of the model was validated using Mediterranean watershed data from southern France and Portugal.

\section{Acknowledgments}

The corresponding writer is grateful to Dr. Donald C. Slack, Prof. and Head of Agricultural and Biosystems Engineering (ABE) Department of the University of Arizona, Tucson, Arizona, for the invitation, hospitality, and support provided during his sabbatical leave. He also wishes to thank the School of Renewable Natural Resources, where this work was completed, with partial support from the Portuguese Fundação para a Ciência e a Tecnologia (FCT) scholarship SFRH/BSAB/778/2008.

\section{References}

Andréassian, V. P. J. (1992). "Comparative hydrology of Mediterranean shrublands." M.S. thesis (Watershed Resources), Univ. of Arizona, Tucson, AZ.

Calvo-Alvarado, J. C., and Gregory, J. D. (1997). "Predicting mean annual runoff and suspended sediment yield in rural watersheds in North Carolina." Report No. 307, Water Resources Research Institute, Univ. of North Carolina, 120.

Di Castri, F. (1981). "Mediterranean-type shrublands of the world." Mediterranean-type shrublands, F. Di Castri, D. W. Goodall, and R. L. Specht, eds., Elsevier, Amsterdam, The Netherlands, 1-52.

Gifford, G. F., Hawkins, R. H., and Williams, J. S. (1976). "Hydrologic impacts of livestock grazing on national resource lands in the San Luis Valley." USDI Bureau of Land Management, Colorado State Office, Lakewood, CO.

Grunsky, C. E. (1908). "Rain and runoff near San Francisco, California." Trans. Am. Soc. Civ. Eng., LXI(1090), 496-543.

Grunsky, C. E. (1915). "Discussion of 'Run-off from rainfall and other data' by A. F. Meyer." Trans. Am. Soc. Civ. Eng., LXXIX, 1165.

Langbein, W. B. (1949). "Annual runoff in the United States." U.S. Geological Survey, Circular 52.

Lu, J., Sun, G., Amatya, D. M., and McNulty, S. G. (2003). "Modeling actual evapotranspiration from forested watersheds across the Southeastern United States." J. Am. Water Resour. Assoc., 39(4), 886-896.

Hawkins, R. H. (1991). "Average annual runoff from precipitation and basin factors in east central Arizona." Proc., Arizona-Nevada Academy of Sciences Annual Meeting, Hydrology Section, 26, Arizona-Nevada Academy of Science, Glendale, AZ, 9.

Hawley, M. E., and McCuen, R. H. (1982). "Water yield estimation in western United States." J. Irrig. Drain Div., 108(IR1), 25-34.

Horton, R. E. (1914). "Discussion on Justin, J. D. 1914. Derivation of runoff from rainfall data." Trans. Am. Soc. Civ. Eng., LXXVII, 345-377.

Instituto da Água, I. P. (2009). "Rios de Portugal. Hidromorfologia dos Rios." Sistema Nacional de Informação de Recursos Hídricos (SNIRH), $\langle$ http://snirh.pt/junior/index.php?menu=2.1〉 (Feb. 5, 2009).

Justin, J. D. (1914). Derivation of Run-Off from Rainfall Data, Vol. LXXVII, ASCE, Reston, VA, 346-363.

Kolterman, C. E., and Gorelick, S. M. (1992). "Paleoclimatic signature in terrestrial flood deposits" Science, 256(5065), 1775-1782.

Nahal, I. (1981). "The Mediterranean climate from a biological viewpoint." Mediterranean-type shrublands, F. Di Castri, D. W. Goodall, and R. L. Specht, eds., Elsevier, Amsterdam, 63-86.

Seaber, P., Kapinos, F., and Knapp, G. (1987). "Hydrologic unit maps." USGS Water Supply Paper 2294. U.S. Geological Survey, Reston, VA.

Sellers, W. D. (1969). Physical climatology, University of Chicago Press, Chicago, 85-89.

Sun, G., et al. (2001). "Effects of timber management on wetland hydrology in the eastern United States." For. Ecol. Manage., 143(1-3), 227-236.

Sun, G., Zuo, C., Liu, S., Liu, M., McNulty, G. S., and Vose, J. M. (2008), "Watershed evapotranspiration increased due to changes in vegetation composition and structure under a subtropical climate." J. Am. Water Resour. Assoc., 44(5), 1164-1175.

Vogel, R. M., Wilson, I., and Daly, C. (1999). "Regional regression models of annual streamflow for the United States." J. Irrig. Drain. Eng., $125(3), 148-157$. 